\title{
Informal care and Labor Supply
}

Elisabeth Fevang Snorre Kverndokk Knut Røed

The Ragnar Frisch Centre for Economic Research, Oslo

\section{UNIVERSITY OF OSLO}

HEALTH ECONOMICS

RESEARCH PROGRAMME

Working paper 2008: 8

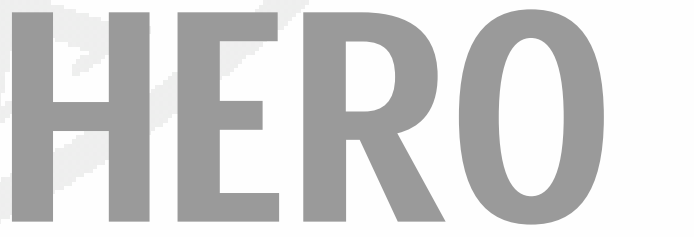




\title{
Informal care and Labor Supply
}

\author{
Elisabeth Fevang \\ Snorre Kverndokk \\ Knut Røed *
}

The Ragnar Frisch Centre for Economic Research, Oslo

29. August 2008

\section{Health Economics Research Programme at the University of Oslo HERO 2008}

Keywords: $\quad$ Elderly care, labor supply, ageing, inheritance.

JEL Classification: J14, J22.

* Corresponding Author: Knut Røed, Ragnar Frisch Centre for Economic Research,

Gaustadalléen 21, 0349 Oslo, Norway. Telephone: + 47229588 13. Fax: + 4722958825.

E-mail: knut.roed@frisch.uio.no.

This research is financed by the Norwegian Research Council through the Welfare Research Program. Thanks to Simen Gaure for programming assistance and to Heidi Gautun, Tor Iversen, and Jos van Ommeren for useful comments. 


\begin{abstract}
Based on Norwegian register data we show that having a lone parent in the terminal phase of life significantly affects the offspring's labor market activity. The employment propensity declines by around 1 percentage point among sons and 2 percentage points among daughters during the years just prior to the parent's death, ceteris paribus. Long-term sickness absence increases sharply. The probability of being a long-term social security claimant (defined as being a claimant for at least three months during a year) rises with as much as 4 percentage points for sons and 2 percentage points for daughters. After the parent's demise, earnings tend to rise for those still in employment while the employment propensity continues to decline. The higher rate of social security dependency persists for several years.
\end{abstract}




\section{Introduction}

Given current demographic trends, most industrialized countries are heading towards a future with shrinking working-age populations relative to the number of (ever older) pensioners. This development is likely to impose large fiscal strains on future workers in order to finance an increasingly overstretched public sector. But future workers may also come under stronger domestic pressures, e.g., in the form of care-needing parents. The combination of increased longevity and deteriorating public finances is expected to raise the demand for informal care within families. ${ }^{1}$ But, given the post-war decline in birthrates and the rise in female labor force participation rates, the potential number of suppliers of such care cannot be expected to match the demand. ${ }^{2}$ Moreover, if informal care substitutes for labor supply and/or human capital accumulation in the formal sector of the economy, a larger role for informal care may add to, rather than alleviate the fiscal burden.

Although it is a firmly established empirical fact that informal care is negatively correlated with labor supply (Charmichael and Charles, 1998; 2003; Spiess and Schneider, 2003; Heitmueller, 2007), the causal relationship running from informal care provision to market labor supply is not easily disentangled from other sources of correlation. The problem of reverse causation is acute in this case, since the decision to provide informal care is likely to be influenced by individuals' labor market outcomes. For example, children with little or no participation in the labor market - for reasons other than the need for family care provision - may face lower time costs and, hence, provide more in-

\footnotetext{
${ }^{1}$ While increased longevity tends to cause a downwards shift in the demand for health services ("acute care") during the final years of life, it causes an even larger upwards shift in the demand for longterm care, see Spillman and Lubitz (2000).

${ }^{2}$ Langset (2006) presents model simulations for the labor demand in the Norwegian long term care sector up to 2050 under different assumptions. In the main scenario, the total informal care supply is assumed to be constant throughout the time horizon for reasons discussed above. As a result, the demand for labor in the formal long term care sector will increase by more than $100 \%$ at the end of the time horizon.
} 
formal care than children who participate fully in the labor market. Moreover, there may exist individual characteristics that affect both the propensity to supply labor in the market and the propensity to provide informal care within the family. Individuals with poor health, for example, may be particularly likely both to stay outside the labor market and to have parents with poor health. Many empirical studies have either not addressed these endogeneity problems at all or relied on potentially invalid or weak instruments; see, e.g., Bolin et al. (2008) or Heitmueller and Michaud (2006) for discussions of the recent literature. A variable commonly used in the literature to instrument parental care is the parent's health status (or, in the absence of health data, their age or education as proxies for health), see Wolf and Soldo (1994), Ettner (1995; 1996), Heitmueller (2007), and Bolin et al. (2008). We will argue that the validity of such instruments is questionable, given the strong intergenerational correlation in health and labor market performance (see, e.g., Marmot, 2004).

In the present paper, we take advantage of the established empirical regularity that the need for care among the elderly is heavily concentrated during the final years of life; see, e.g., Emanuel et al. (1999), Romøren (2003), Seshamani and Gray (2004), Polder et al. (2004) and Wolff et al. (2007). Hence, rather than evaluating the impact on labor market outcomes of actually observed care provision, we examine the time path of labor market outcomes during the final years of parents' lives as well as the years after the decease of the parents. The demise of a parent may also affect labor market activity through the changes in budget constraints caused by inheritance; see, Holtz-Eakin et al. (1993) and Joulfaian and Wilhelm (1994). To the extent that individuals optimize with respect to an intergenerational budget constraint, as suggested by Barro (1974), expected inheritance does not alter labor market behavior around the time of the parents' demise. However, with credit constraints, and with uncertainties in longevity as well as in the size of the be- 
quest, we would expect labor supply to shift downwards in response to inheritance. It is conceivable that this effect builds up gradually as the moment of parents' death approaches, both because the time and the size of a forthcoming inheritance can be assessed with greater precision and because bequests/gifts are sometimes paid out in advance. A key concern in our analysis is therefore to disentangle the effects on labor supply arising from the demand for informal care from the potential income effects associated with a realized or forthcoming bequest. It is also conceivable that the loss of - or the process of losing - a parent causes grief reactions, which in turn reduce the offspring's ability to work. These reactions may sometimes be strongest in the period prior to the parent's death. Schultz et al (2003) show that caring for persons with dementia result in higher levels of depressive symptoms, but after death the caregivers tend to recover from depressive symptoms. In cases of more abrupt (unexpected) death, adverse psychological reactions may come after the loss of the parent instead.

Our empirical basis is complete administrative register data from Norway, which during 1993-2005 keep track of employment status, yearly earnings, and social security claims for all Norwegian citizens. The data contain family identifiers, which make it possible to date important family events, such as the demise of parents, and to identify siblings. The data also contain information about geographic proximity between parents and offspring and about the parents' economic wealth (the expected size of the inheritance).

The extent to which the existence of a care-needing elderly family member affects the offspring's labor market behavior obviously depends on both the level of the required care and on the access to care provided by the market or by the public sector. Like other Scandinavian countries, Norway is characterized by a comprehensive system of publicly provided care for elderly and disabled individuals, in the form of nursing homes and community nursing. The user payment for these services is means-tested against own in- 
come (but not against the income of the offspring), and the level of support is supposed to be determined by individual needs rather than by ability to pay. In 2000, publicly funded long-term care took hold of around 1.8 per cent of the Norwegian GDP, compared to 0.7 per cent in the United States and 0.8 per cent in the United Kingdom (OECD, 2005). ${ }^{3}$ The quality of publicly provided care is of course subject to substantial variation. It is supposed to be sufficient for covering basic needs; hence the extent to which relatives need to adjust their own labor market behavior in order to care for elderly parents is likely to be limited. However, many relatives view the level of publicly provided care as insufficient, particularly with respect to coverage of "social needs". According to Norwegian timeuse surveys (Vaage, 2002), approximately eight per cent of the Norwegian adult population provided informal care to a person outside his/hers own household on a randomly selected day in 2000. The average time use (among those who provided care) was 1.3 hours. Not all of this can be attributed to the elderly, however. Based on some supplementary questions that were used in the Statistics Norway's labor force sample survey in the second quarter of 2005, it is estimated that around 5.3 per cent of the adult population regularly provide care for elderly relatives or other adults. In a recent survey, Gautun (2008) found that 70 per cent of the informants in the age group 45 to 65 who still had at least one parent alive, to some extent combined the roles of paid work and parental care/assistance. Further, in a detailed longitudinal study of all elderly above 80 years in the Norwegian municipality of Larvik (encompassing 434 individuals), Romøren (2003) showed that the average duration of the period with serious functional disabilities prior to

\footnotetext{
${ }^{3}$ The long term care sector is somewhat in between hospitals and informal care, meaning that some of the services provided by the sector can also to some extent be provided by the family or at a hospital. Different countries or cultures may have different organizations of these services that may explain the difference in the figures above. See also Herolfson and Daatland (2001) for an international comparison.

${ }^{4}$ Informal and formal care are not necessary complete substitutes. Motel-Klingebiel et al. (2005) find in an international comparison that the welfare state does not crowd out family care, while Bonsang (2008) finds informal care to be a weak complement to nursing care.
} 
death is 3.2 years for women and 1.8 years for men (only 9 percent experienced no functional disabilities prior to death). However, informal care is typically provided for much longer periods than that; in cases where an offspring is the primary care provider, roughly 40 percent of the care-periods stretch beyond five years. And since many of the elderly end their lives in care-institutions, the demand for family care is not always at its largest in the period just prior to death, but rather in the period just prior to admittance into the care-institution. There are no social programs in Norway particularly targeted at offspring who provide care/assistance to a parent, except that workers are entitled to up to 20 days unpaid leave in the terminal phase of each parent's life.

The main findings of our paper are that having a lone parent in the terminal phase of life holds back overall earnings for both men and women and also causes labor market participation to decline and social security dependency (particularly related to long-term sickness absence) to rise. While the employment effect is strongest for daughters, the social security effect is strongest for sons. Employment rates continue to decline after the demise of the lone parent, while social security dependency rates persist at the high level experienced during the year of the parent's death.

\section{Theoretical considerations}

The theoretical literature emphasizes several motives for a child to provide care to its elderly parents, such as altruism, duty, social norms, reciprocity, direct payments, strategic bequest motives, and the provision of a demonstration for own children regarding the desired behavior towards elderly parents. Regardless of the motive, it is clearly the case that the more time devoted to informal care provision, the less time available for leisure and market work. In order to organize our thinking about the various tradeoffs involved, we take the altruistic motive as a point of departure; see, e.g., Chang and White-Means (1995), Nocera and Zweifel (1996), and Kuhn and Nuscheler (2007). In the altruistic 
model, the child takes the utility of the parents into account when determining own behavior. The basic idea can be illustrated within a simple three-period model, where period 0 is the period with healthy parents, period 1 is the terminal phase of parents' life, where informal care is demanded, and period 2 is the period after the parent's death. Disregarding the issue of discounting, the offspring's overall utility can be expressed as

$$
\Omega=U\left(X_{0}, L_{0}, E\right)+U\left(X_{1}, L_{1}, E\right)+\beta V(Z+\bar{Z})+U\left(X_{2}, L_{2}, E\right),
$$

where $X$ is consumption, $L$ is leisure, $E$ is human capital (education), and $Z$ is the amount of care provided by the offspring to the parent in period 1 , and $\bar{Z}$ is the amount of care provided by others. $V$ can be interpreted as the utility function of the parent, and $\beta$ is the weight it obtains in the offspring's utility. Both $U$ and $V$ are strictly concave functions and we assume that all the cross-derivatives of $U$ are positive. A key idea is that human capital potentially enhances the transformation of goods and leisure into utility (Michael, 1973) while leaving the productivity of informal care-provision unchanged (Romøren, 2003; Gautun, 2003). This implies that low-skilled individuals have a comparative advantage in care-provision.

The child's intertemporal budget constraint is determined by the total time available in the three periods $\left\{T_{0}, T_{1}, T_{2}\right\}$, by the wage and price levels $\{w, p\}$, by the size of the inheritance $M$, and by the time needed to provide each time-unit of effective care $(1+a)$, i.e.,

$$
p X_{0}+p X_{1}+p X_{2}=w\left(T_{0}-L_{0}\right)+w\left(T_{1}-L_{1}-(1+a) Z\right)+w\left(T_{2}-L_{2}\right)+M
$$

If the offspring is credit constrained we may alternatively think of the budget constraints as being periodic, with no transfers from one period to another. We assume here that the 
size of the inheritance is unaffected by child's choice of care effort; i.e., we rule out strategic bequest behavior. ${ }^{5}$

Equipped with this basic modeling framework, we now discuss the impacts on labor supply of having a care-needing parent in the terminal phase of life. A more general and formal analysis is provided in a separate companion paper available at www.frisch.uio.no/docs/informal_care.html.

Optimally determined levels of leisure, consumption, and care provision in period 1 requires that the marginal rate of substitution between consumption and care-giving equals the ratio of the consumption price and the time cost of care giving $(p /(w(1+a)))$, unless a corner solution is obtained with either $Z=0$ or $L_{1}=0$. In addition, the marginal rate of substitution between leisure and care-giving equals $1 /(1+a)$, since the time cost is the same for these two alternatives. With equal time budgets across periods $\left(T_{0}=T_{1}=T_{2}\right)$ and in the absence of credit constraints and uncertainty, this model predicts labor supply to be lower in period 1 than in periods 0 and 2 (provided an interior solution to the optimization problem), with labor supply being equal across the pre- and post-care periods. Even with credit constraints, we normally expect labor supply to decline from period 0 to period 1 , as the reduction in available time for leisure and consumption is distributed between the two goods in order keep the marginal rate of substitution constant. With credit constraints, the labor supply in period 2 is unequivocally lower than in period 0 , since the inheritance entails an income effect raising both consumption and leisure in period 2. Compared to

\footnotetext{
${ }^{5}$ According to Norwegian legislation at least two thirds of the inheritance - up to a limit of 1 mill. NOK per child - must be shared equally between siblings. In addition, the progressivity of the inheritance tax system strongly favours equal sharing. To the extent that parents deviate from the equal-sharing norm, the motivation is typically to compensate for differences in needs, rather than to pay for help and services. Survey-based evidence reported by Halvorsen and Thoresen (2005) shows that only 1 percent of Norwegian parents with adult children think that intergenerational transfers should be disproportionably allocated to "the most helpful child"; 73 percent prefer equal sharing, while 23 percent prefer a division based on needs. These views also turn out to be reflected in actual gift behaviour, i.e., there are no indications that children who help their parents a lot receive more gifts, compared to their siblings (Halvorsen and Thoresen, 2005).
} 
period 1, labor supply may rise or fall, depending on whether the removal of the care requirements or the income effects arising from inheritance dominates.

In reality, neither the perfect-market-perfect-foresight model nor the creditconstraint model provides a realistic description of the environment in which labor supply decisions are made. With imperfect credit markets and/or uncertainty regarding the timing and the size of a forthcoming inheritance, we may expect observed behavior to lie somewhere between the predictions from the two "extreme" versions of the model. In particular, we may expect the income effect of the forthcoming inheritance to arise gradually as period 2 approaches, reflecting that the uncertainty regarding the timing and size of the inheritance becomes smaller and/or that parts of the inheritance are paid out in advance. From an empirical point of view, this makes it difficult to disentangle the labor supply impacts of care requirements from the impacts of inheritance. However, by looking at the interactions between labor supply behavior over the three periods and the other key parameters in our model - and comparing them with observed interactions in the data - we may nevertheless shed some light on the empirical relevance of the different explanations.

Consider first the level of care provided by others $\bar{Z}$. An increase in $\bar{Z}$ unequivocally reduces informal care-giving and increases labor supply in period 1 . If $\bar{Z}$ is sufficiently high (low), a corner solution may be chosen, with $Z=0\left(L_{1}=0\right)$. In the empirical analysis, we obtain proxies for $\bar{Z}$ by exploiting data on siblings and on variation in public care-provision across municipalities. ${ }^{6}$ A rise in the time-cost of care-giving $a$ implies that more time is required to provide a given level of care, yielding a reduction in labor supply. On the other hand, it also reduces the optimal level of care provision. Hence, the

\footnotetext{
${ }^{6}$ Note that we treat the care provided by others as exogenous. Several papers have studied the interactions or strategic behaviour of siblings when the parent's health is considered a common good, see, e.g., Konrad et al. (2002), Engers and Stern (2002), Rainer and Siedler (2005) and Callegaro and Pasini (2007). There are also papers treating the publicly provided care as endogenous; see Van Houtven and Norton (2004).
} 
overall impact of the time-cost on labor supply is theoretically indeterminate. In the empirical analysis we use the geographical distance between the child and the parent as a proxy for the time-cost of care.

The level of the inheritance $M$ affects the intensity of care-giving positively - and the level of labor supply negatively - in the perfect-credit-market model, while having no impact on care-giving and period 1 labor supply in the credit-constraint model. The pure care-motivated labor supply responses in period 1 may in any case be identified on the basis of individuals with no (or very low) expected inheritance.

Our simple model can also be used to examine the disparities in labor supply responses towards care-needing parents between individuals with different levels of human capital $E$. For a given wage rate $w$, we find that the level of care-giving declines with the level of human capital, since human capital is assumed to increase the utility of consumption and leisure, while leaving the productivity of care-provision unchanged. Under reasonable conditions, the extra time from less care-provision is distributed between the two goods of leisure and consumption; hence labor supply is likely to exhibit a particularly positive relationship with human capital in the period with demand for parental care (period 1). The wage rate also increases with human capital. A higher wage rate, $w$, entails the usual income and substitution effects for both leisure and care-giving with indeterminate net effects. In the empirical analysis, we are not able to separate the impacts of education (human capital) and wages, since wage rates are generally unobserved. According to the existing empirical literature, labor supply tends to be less elastic the higher is human capital; see, e.g., Røed and Strøm (2002) for an overview of the relevant literature. We may therefore guess that the impact of care-requirements on own labor supply is also smaller the higher is the level of human capital. 
Finally, we turn to the sizes of the overall time budgets $\left\{T_{0}, T_{1}, T_{2}\right\}$. Different phases of life may be characterized by different types of time-constraints. In particular, we may interpret a period with own dependant children as a period with reduced time available for purposes of work, leisure and care for parents. A reduction in $T_{1}$ generally reduces labor supply in period 1 . However, it may also raise the likelihood of ending up in a corner solution with $L_{1}=0$, in which case care-giving may actually increase. Limited time budgets may place individuals' with care-needing parents in a time-squeeze. For some workers, it may be difficult to reduce the number of hours worked in the market even when this is the optimal choice, e.g., because the employer demands full-time work or because the employee foresees that reduced work-hours adversely affects the future labor market career. In such cases, we would expect the level of long-term sickness absence and other forms of social security dependency to rise, and the level of employment to decline due to the negative health effects of the time-squeeze.

\section{Data and Descriptive statistics}

Our empirical analysis is based on administrative register data describing the life histories of all Norwegians from 1993 to 2005, with earnings and employment records dating back to 1980 (including paid employment as well as self-employment). The data we use contain information about age, gender, municipality, employment status, yearly earnings, and all kinds of social security transfers (the latter on a monthly basis). They also include information on family-ties, making it possible to date the (exact) time of parents' deaths, to compute the expected level of inheritance, and to identify siblings. ${ }^{7}$ Our analysis focuses on Norwegian (native-born) individuals born between 1933 and 1967 who lost a parent between 1993 and 2005 while they themselves were between 38 and 66 years. In total, the

\footnotetext{
${ }^{7}$ Note that family identifiers are incomplete for individuals born before 1950 , since the family tie is often missing for offspring who moved out of their parents' home before the 1970 census.
} 
risk-group, i.e., individuals born in this period, consists of around 1.8 million persons; see Table 1. Out of these, around half a million individuals actually lost a parent during the relevant time period (1993-2005), and 308,706 lost a lone parent.

\section{- Table 1 around here -}

Our main empirical strategy is to examine the time-path of various labor market outcome measures during a period of up to 15 years before and 12 years after the death of parents. We focus on three different outcome measures; a) yearly earnings, b) employment propensity, c) social security dependency. ${ }^{8}$ Before we set up the statistical models used to identify the effects of interest, we take a brief look at how our three outcome measures tend to develop in the years prior to and just after the death of parents. We do that by looking at outcomes for individuals who are $k$ periods away from the death of a parent, relative to all individuals in Norway of the same age and gender, measured at the same point in calendar time. Figure 1 shows the percentage point difference in outcomes during the seven years prior to, and the three years after, a parent's demise (earnings/employment is recorded annually, while social security dependency is recorded monthly). ${ }^{9}$ For example, looking at the curve for earnings effects of a lone parent demise in the upper left hand panel of the figure, we note that individuals who are destined to ex-

${ }^{8}$ Employment is for each year defined as having earnings or self-employment income sufficiently high to earn pension points in the Public Pension System. Currently (2007/2008) the required income level is 66,812 NOK. Social security dependency is defined on a monthly basis, and implies that social security claims are made during the month in question. The following claims are included: unemployment insurance, sickness absence benefits (for absence spells lasting at least 16 days), rehabilitation benefits, disability benefits, and social assistance.

${ }^{9}$ Let $y_{e i}(g, a, t, k)$ be outcome measure $e$ for individual $i$ of gender $g$ measured at age $a$ in period $t$, given that $t$ is $k$ periods away from an event of interest; i.e., the death of a parent. We can then write the mean outcome conditional on distance from the event relative to the mean outcome for all individuals of same gender and age at the same time, but unconditional on the distance to the event, as

$$
\mu_{e k}=\sum_{i \in N}\left[\frac{y_{e i}(g, a, t, k)}{\sum_{j \in N^{g a t}} y_{e j}(g, a, t)}\right] .
$$


perience the loss of a lone parent in exactly seven years on average have 2.5 percentage points lower earnings than all Norwegians at the same age/gender/time. As the moment of the parent's death approaches the difference increases, and in the year of the parent's death it reaches -4.3 percentage points. The difference continues to increase even after the parent's death, and reaches around -5.4 percentage points after three years.

- Figure 1 around here -

Figure 1 illustrates a number of important points. First, conditional on age and calendar year, the timing of the parents' demises seem to be associated with substantial differences in employment, earnings, and social security dependency long before these events actually occur. While the loss of a married parent is generally associated with favorable labor market performance, the loss of a lone parent is associated with inferior labor market performance. This suggests that the events of losing a married or lone parent during own age 38-66 cannot be considered randomly assigned in relation to the offspring's own health. Second, the time-paths of the differentials do seem to indicate causal effects. Labor supply declines as the time of parent's demise approaches, and it declines much more for the event of lone parent's death than for the event of a married parent's death. Third, labor supply continues to decline after the death of both parents. Fourth, social security claims make a jump during the three month period surrounding the parents' death, primarily reflecting increased long-term sickness absence in this period. However, social security dependency also tends to remain at a relatively high level during the years afterwards, particularly after the loss of a lone parent.

\section{Empirical analysis}

In this section, we set up statistical models aimed at recovering the causal impacts on labor market outcomes of having - or recently having had - a lone parent. We focus entirely on lone parents in this section, since the descriptive analysis in the previous section indi- 
cated that the loss of a married parent have minor impacts on offspring's labor market activities (married parents in the terminal phase typically have their spouse, rather than their offspring, as their primary care provider). Although all parents obviously die at some point, the descriptive statistics presented in the previous section indicate that the timing of this event in the offspring's life-course cannot be assumed independent of offspring characteristics. Healthy individuals can expect to lose their parents at a higher own age than unhealthy individuals, since there is a positive intergenerational correlation in health, and healthy individuals also have higher earnings than unhealthy individuals. Hence, individuals who have not yet lost their parents at the end of our observation window may not be directly comparable to those who have. Moreover, since we do not know when the former of these individuals lose their parents, we also do not know how far away they are from this event. Our statistical analysis is therefore limited to individuals who actually experienced the loss of a lone parent during the period from 1993 to 2005 . Our basic idea is to examine how the various labor market performance indicators are affected by the time distance to the event. For this purpose, we exploit data on employment and earnings back to 1980, but we disregard outcomes experienced more than 15 years before the parent's death or before the age of 35 . All the outcomes, including social security dependency, are defined on a yearly basis. A person is defined as being dependent on social security transfers in a given year if such transfers were recorded for at least three months during that year. The outcomes are modeled separately for men and women within a regression framework; i.e.

$$
y_{\text {rit }}=f\left(\sigma_{r c t} S_{c t i}+\delta_{r k} d_{t i}+u_{r i t}\right)
$$

where $y_{\text {rit }}$ is an outcome measure $r$ ( $r=$ earnings, employment, social security dependency) for individual $i$ at time $t, s_{c t i}$ is a vector of dummy variables representing birth cohort $c(c=1933, \ldots, 1967)$ interacted with year of outcome measurement $t(t=1980, \ldots, 2005)$, 
$d_{t i}$ is the number of years away from the death of a lone parent $(k=\leq-9,-8, \ldots, 0, \ldots, 4, \geq 5), u_{r i t}$ is an error term, and $\left(\sigma_{r c t}, \delta_{r k}\right)$ are the parameters to be estimated. ${ }^{10}$ The dichotomous outcome measures (employment, social security dependency) are modeled in terms of clustered Logit equations, with $f(a)=\exp (a)(1+\exp (a))^{-1}$. Our estimation procedure takes into account that the error terms may be correlated over time for each individual, and only robust confidence intervals are reported. The continuous outcome measure (yearly earnings) is modeled conditional on employment, and we use the log of yearly earnings as the left hand side variable, with $f(a)=a$ in Equation (3). If the loss of a lone parent affects employment propensity, this potentially induces a sorting bias into its estimated impacts on earnings. We therefore model the earnings effect by means of a fixed effects (within) estimator.

To estimate a separate effect of each cohort-year combination may appear overly ambitious, since it involves the usage of almost 700 dummy variables (35 cohorts, each observed for on average around 20 years). However, since we attempt to identify a presumably moderately sized effect from data with large outcome variations due to other factors (age and time), it turns out that it is critical to avoid invalid restrictions on the control variables. ${ }^{11}$ Our focus is of course on the impact of the lone parent's demise $\left(\delta_{r k}\right)$. In order to trace out average effects, we start out by estimating the model on the full male and female datasets, including all individuals who lost a lone parent; see Table $1 .{ }^{12}$ We then estimate the model separately for various subgroups to examine the extent to which the effects vary according to i) the offspring's age, ii) the number of siblings, iii) the level of

\footnotetext{
${ }^{10}$ The cohort-time dummies may of course alternatively be interpreted as cohort-age dummies.

${ }^{11}$ In the fixed effects model, a separate dummy for each possible cohort-year combination implies that one multicollinear vector is introduced for each cohort. Hence, one normalization is required for each cohort in this model.

${ }^{12}$ We disregard individuals who lost a lone parent more than once during the relevant time-period (this is possible if the parents are divorced). We also disregard individuals who did not reside in Norway in the year of their parent's death.
} 
human capital, iv) the geographical distance to the demised parent, v) characteristics of the publicly provided care in the parent's municipality, and vi) the size of the expected inheritance. The latter three groupings require data that are available for later years only; hence significant numbers of observations (up to a third) are lost in these exercises. Ideally, we would have formulated multivariate models designed to pick up the partial impacts of the various explanatory variables. However, multivariate models require some functional form restrictions on the $\delta_{r k}$-vectors and on the way they interact with the various explanatory variables. As it turns out, we have not been able to find a sufficiently robust model specification for this purpose.

Section 4.1 presents the main results of our regression analysis. We focus entirely on the labor supply responses to the loss of a lone parent. These impacts are presented graphically (for a representative offspring) with 95 percent confidence intervals. Sections 4.2-4.5 compare the estimated labor supply responses for various sub-groups. For ease of exposition, we draw confidence intervals for one group at a time, and represent the comparison group solely by point estimates (the two confidence intervals are typically of similar size). A complete list of estimates with standard errors can be downloaded from our web-page www.frisch.uio.no/docs/informal_care.html. This page also contains a description of the sizes of the datasets (and groups) used for the various regressions, and the reasons why some observations are lost.

\subsection{Overall impacts of a lone parent's death}

Figure 2 presents our key regressions results. The impacts on employment and social security dependency are evaluated in terms of percentage point deviation from a reference level nine years (or more) prior to the lone parent's death. The reference levels are chosen separately for men and women to match the observed employment and social security 
rates in the data. ${ }^{13}$ The impacts on earnings (conditional on employment) are evaluated in terms of percent earnings deviation relative to a situation with at least nine years until the loss of a lone parent. These numbers follow directly from the estimated log-earnings equation.

- Figure 2 around here -

Our results indicate that the offspring's employment propensity drops in the years just prior to a lone parent's death, ceteris paribus. The drop is around 1 percentage point for sons and 2 percentage points for daughters. The decline in employment propensity continues during the first years after the parent's demise. Conditional on remaining in the workforce, offspring earnings are relatively stable in the 10 year period prior to the lone parent's death, although a very small decline seems to occur during the year of the parent's death. Some time after the demise of the lone parent, earnings tend to increase by around 1 percent for sons and 2 percent for daughters, indicating that the earnings level may have been slightly restrained for a relatively long period prior to the loss of the lone parent. The most conspicuous result in Figure 2, however, is that social security dependency increases sharply during the years prior to the loss of a lone parent. The probability of becoming a long-term (at least three months) social security claimant rises by almost 4 percentage points for men and by 2 percentage points for females. And the higher risk of social security dependency seems to persist for several years after the parent's demise. It is of interest to note that the labor market responses towards a care needing parent are quite similar for sons and daughters. But, while daughters to a somewhat larger extent than men respond by pulling out of the labor force, they are to a lesser extent than men inclined to claim social security benefits as a result of the parent's care needs.

\footnotetext{
${ }^{13}$ For employment, these reference levels are 96 percent for men and 79 percent for women. For social security dependency, the reference levels are 19 percent for men and 23 percent for women.
} 
Taken together, these results are clearly consistent with the hypothesis that informal care requirements reduce labor supply at the extensive as well as the intensive margin, although some of the effects may be viewed as quantitatively insignificant. The negative employment effects identified after the lone parent's death also suggest that the improved liquidity arising from inheritance does play a significant role for labor market participation choices. However, inheritance cannot explain the small rise in earnings occurring after the parent's demise (conditional on employment). The significant rise in social security dependency also indicates that many offspring are subject to a difficult timesqueeze in the terminal phase of their own parents' lives. This interpretation is confirmed by a recent interview survey encompassing middle aged Norwegians, in which 57 percent of the respondents in the relevant group report a burdensome "twin pressure" from work and care obligations (Gautun, 2008). The social security effect is stronger for men than for women, probably reflecting that fewer men decide to pull voluntarily out of the labor force as a result of pressure and stress arising from a parent's informal care requirements. The failure of the social security propensity to return to its "reference" level after the parent's demise may indicate, however, that the improved liquidity associated with an inheritance implies that social security becomes an affordable option for a larger share of the population.

\subsection{Care provided by others}

To the extent that offspring's labor supply behavior is affected by parents' informal care demands, the magnitudes of the responses are likely to be sensitive towards the level of care provided by others. The main alternative providers of care to a lone parent are the offspring's siblings and the municipality. We have estimated the impacts of parental death separately for lone children and for offspring with at least one sibling; see Figure 3. From the theoretical discussion provided in Section 2, we expect lone children to be more 
strongly affected by their lone parent's death, both because they have nobody to share the informal care responsibility with ( $\bar{Z}$ is low) and because they can expect a larger inheritance ( $M$ is large). This prediction is confirmed by the data. In particular, we note that employed lone children - in contrast to offspring with siblings - reduce their earnings quite significantly (by almost 2 percent) during the years prior to the parent's demise. For lone daughters, there is also a much stronger negative employment response than for daughters with siblings.

\section{- Figure 3 around here -}

There is not much observed variation in the municipalities' overall supply of elderly care, and the national system for allocation of funding is indeed designed to ensure equal standards across the whole country. There has, however, been some variation in the weights that different municipalities attach to institutionalized versus home-based care provision. One may hypothesize that home-based care to a larger extent than institutionalized care relies on contributions from family members. Based on accounting data from the so-called KOSTRA database (administered by Statistics Norway) we have divided our population into two equally sized groups, depending on their municipalities" "institutionshare" in overall care expenditures. We use information about the municipality the same year as the parent die. ${ }^{14}$ Municipalities with an institution-share above the median are denoted institution oriented, while the rest are denoted home care oriented. ${ }^{15}$ Figure 4 displays the estimated labor supply responses by municipality type. Although the statistical confidence intervals are too wide to draw any firm conclusions, the results indicate indeed that both the negative employment effect and the positive social security dependency ef-

\footnotetext{
${ }^{14}$ In our data we do not have information about the parent's place of residence before 1998, which means that we lose a lot of observations. Since we know the fraction of overall care expenditures used in care institutions only in the years after 2000, we use the fraction lying closest to the parent's death.

${ }^{15}$ Note that variation in institution shares may not solely reflect different priorities, but also differences in the composition of the care-needing population.
} 
fect of having a lone parent in the terminal phase of life are somewhat larger in a home care oriented municipality than in an institution oriented municipality, particularly for daughters.

- Figure 4 around here -

\subsection{The role of inheritance}

To which extent do the behavioral impacts of a lone parent's death arise from the income effects of inheritance $(M)$ ? We examine this issue by exploiting data on the parent's wealth in the year prior to his/hers death. The key idea is to identify a group of individuals with little or no inheritance, and to estimate the causal impacts of the lone parent's death separately for them. The required information on parent's wealth can be collected from the tax registers (since Norwegian citizens pay a wealth tax). We calculate expected inheritance by dividing the parent's wealth on the number of siblings in the family. We then split the population according to positions in the expected inheritance distribution, such that the low-inheritance group consists of the third with the lowest expected inheritance. In order to ensure that the presumed low-inheritance-group does not comprise individuals for whom the low expected inheritance upon the parent's death results from large transfers in advance, we also require that their parents' joint income during their 50's belongs to the lowest third in the distribution of all parents joint incomes during this ageperiod. Data on the parents' incomes during their 50's are collected from pension point accrual register covering all citizens of Norway.

The estimation results shown in Figure 5 indicate that the income (liquidity) effects arising from inheritance are important for labor supply behavior around the time of a lone parent's demise. First, the employment responses are strongest for offspring who expect a significant inheritance. Second, the rise in earnings after the parent's death (conditional on employment) are clearly largest for offspring with little or no inheritance, sug- 
gesting that the income effect arising from inheritance does moderate these responses among other workers. And finally, rise in social security propensity is much larger among high-inheritance than among low-inheritance offspring, indicating that the increased wealth arising from inheritance actually makes a life on social security more affordable. The results should be interpreted with care, however, since we cannot rule out that the low-inheritance population consists of offspring with lower-than-average labor supply responses for reasons that are not directly related to inheritance.

- Figure 5 around here-

\subsection{Human capital}

Based on the model outlined in Section 2, we expect the magnitude of the labor supply response with respect to informal care requirements to decline in the offspring's human capital $(E)$. In Figure 6, we compare the estimated responses for two education groups those with only compulsory education and those with college or university education. The theoretical prediction is clearly confirmed for sons, while the pattern for daughters is more mixed. Conditional on employment, it seems that the labor supply responses declines with human capital even for daughters. However, at the extensive margin, the daughters' labor supply responses seem to increase with human capital. One possible explanation for this phenomenon is that since a large fraction of college educated females work in the relatively low-paid education and healthcare sectors, the skill premium in female wages tends to be much lower than the skill premium in male wages (Hægeland and Kirkebøen, 2007, pp. 14-15).

- Figure 6 around here - 


\subsection{The time-cost of care provision}

While human capital affects the opportunity cost of care provision, there are also direct costs. Offspring, who reside in another region than their parent, face particularly high time and travel costs. From the discussion in Section 2, we know that a rise in the timecost of care-giving (a) has an ambiguous effect on labor supply; on the one hand it implies that more time is required to provide a given level of care (which partially displaces labor supply), on the other hand it implies that the optimal level of care declines. Figure 7 present the results from models that are estimated separately for offspring who do and do not reside in the same "travel-to-work area" as the parent. While employed offspring who live in the same region as their lone parent experience a significant increase in earnings after the parent's demise, no such impacts can be seen among offspring living in another region. However, for daughters it also seems to be the case that those who reside in another travel-to-work area than their parent experience the strongest negative employment impacts. One reason for this may be that women are more altruistic or feel a stronger duty to help their parent than men even if this means a long travel.

- Figure 7 around here -

\subsection{Age}

The labor supply impact of informal care requirements may vary across age groups because different age groups have different time or budget constraints. As it turns out, however, the estimated impacts are quite similar across age groups; see Figure 8.

- Figure 8 around here -

\section{Conclusion}

Based on administrative register data from Norway, we have shown that offspring's labor supply is negatively affected by having a lone parent in the terminal phase of life, both at 
the extensive and the intensive margin. While the impacts on employment and earnings are quantitatively small, the impacts on social security dependency are quantitatively large, particularly for sons. The probability of being a long-term social security claimant defined as claiming benefits or social assistance for at least three months during a year, due to, e.g., sickness absence, rehabilitation, unemployment, or disability - rises on average by 2-4 percentage points during the final years of a lone parent's life. Also, the higher level of social security dependency persists for many years after the parent's demise. The rise in social security dependency is particularly large for offspring who receive a significant inheritance from their demised parent, suggesting that the rise in wealth makes a life on social security more affordable for some individuals.

There are no social programs in Norway targeted particularly at workers with care-needing parents. To some extent it seems that the offspring circumvent this problem by claiming sick themselves. This finding is in accordance with survey based evidence reported by Gautun (2008). Claims of own sickness does not necessarily imply that the offspring are shirking. Stress and pressure may affect the offspring's health as well as their ability to work with a given health-problem. And all health related social security claims in Norway are certified by a physician.

Norway combines a comprehensive system of publicly provided elderly care with a relatively generous welfare support system for workers who cannot work for reasons of sickness, disability, or unemployment. Taken together, these institutional features may have contributed to de-privatize the responsibility for elderly care. The results presented in this paper suggest, however, that offspring still have a significant role to play in taking care of their own parents. Informal care substitutes for the supply of labor in the market. But to some extent the offspring - and in particular the sons - pass their costs on to the public purse through the social security system. 


\section{References}

Barro, R. (1974) Are Government Bonds Net Wealth? Journal of Political Economy, Vol. $82,1095-1117$.

Bolin, K., Lindgren, B. and Lundborg, P. (2008) Your Next of Kin or Your Own Career? Caring and Working Among the 50+ of Europe. Journal of Health Economics, Vol. 27, Issue 3, 718-738.

Bonsang, E. (2008) Does informal care from children to their elderly parents substitute for formal care in Europe?, CREPP Working Papers 2008/01, CREPP, University of Liège.

Callegaro, L. and Pasini, G. (2007) Social interaction effects in an inter-generational model of informal care giving, Working Paper no. 10, Department of Economics, University of Venice.

Carmichael, F. and Charles, S. (1998) The Labor Market Costs of Community Care. Journal of Health Economics, Vol. 17, 747-765.

Carmichael, F. and Charles, S. (2003) The Opportunity Cost of Informal Care: Does Gender Matter? Journal of Health Economics, Vol. 22, 781-803

Chamberlain, G. (1980) Analysis of Covariance with Qualitative Data. Review of Economic Studies, Vol. 47, 225-238.

Chang, C. F. and White-Means, S. I. (1995) Labor supply of informal caregivers, International Review of Applied Economics, Vol. 9. No. 2, 192-205.

Emanuel, E. J., Fairclough D. L., Slutsman J., Alpert H., Baldwin D., and Emanuel, L. (1999) Assistance from family members, friends, paid care givers, and volunteers in the case of terminally ill patients. New England Journal of Medicine, Vol. 341, 956-963. 
Engers, M. and Stern S. (2002) Long-term care and family bargaining, International Economic Review, Vol. 43, No.1, 73-114.

Ettner, S. L. (1995) The Impact of "Parent Care" on Female Labor Supply Decisions, Demography, Vol. 32, No. 1, 63-80.

Ettner, S. L. (1996) The Opportunity Cost of Elder Care. Journal of Human Resources, Vol. 31, No. 1, 189-205.

Gautun, H. (2003) Økt individualisering og omsorgsrelasjoner i familien. Omsorgsmønstre mellom middelaldrende kvinner og menn og deres gamle foreldre.. Report 420, FAFO, Oslo.

Gautun, H. (2008) Hvordan kombinerer eldre arbeidstakere jobb med omsorgsforpliktelser for gamle foreldre? Søkelys på arbeidslivet, No. 2, 2008.

Halvorsen, E. and Thoresen, T. O. (2005) The relationship between altruism and equal sharing. Evidence from inter vivos transfer behavior. Discussion Papers No. 439, Statistics Norway, Research Department.

Herolfson, K. and Daatland, S. O. (2001) Ageing, intergenerational relations, care systems and quality of life - an introduction to the OASIS project, NOVA Report 14/2001, NOVA - Norwegian Social Research.

Hægeland, T. and Kirkebøen, L. J. (2007) Lønnsforskjeller mellom utdanningsgrupper. SSB Notat 2007/36 (www.ssb.no/emner/06/90/notat_200736/notat_200736.pdf).

Heitmueller, A. (2007) The Chicken or the Egg? Endogeneity in Labor Market Participation of Informal Carers in England. Journal of Health Economics, Vol. 26, Issue 3, 536-559.

Heitmueller, A. and Michaud, P-C. (2006) Informal Care and Employment in England: Evidence from the British Household Panel Survey. IZA Discussion Paper No. 2010 . 
Holtz-Eakin, D., Joulfaian, D, and Rosen, H. S. (1993) The Carnegie Conjecture: Some Empirical Evidence. The Quarterly Journal of Economics, Vol. 108, No. 2, 413436.

Joulfaian, D. and Wilhelm, M. O. (1994) Inheritance and Labor Supply. The Journal of Human Resources, Vol. 29, No. 4, 1205-1234.

Konrad, K., Künemund, H., Lommerud, K. E. And Robledo, J. R. (2002) Geography and the Family, The American Economic Review, Vol. 92, No. 4, 981-998.

Kuhn, M. and Nuscheler, R. (2007) Optimal Public Provision of Nursing Homes and the Role of Information. Rostock Centre Discussion paper no. 13, Rostock Centre for the study of Demographic Change.

Langset, B. (2006) Arbeidskraftbehov i pleie- og omsorgssektoren mot år 2050, Økonomiske analyser, No. 4, 56-61.

Michael, R. T. (1973): Education in Nonmarket Production, Journal of Political Economy, Vol. 81, No. 2, Part 1, 306-327.

Motel-Klingebiel, A., Tesch-Roemer, C. and von Kondratowitz, H.-J. (2005) Welfare states do not crowd out the family: evidence for mixed responsibility from comparative analyses, Ageing \& Society, Vol. 25, 863-882.

Nocera, S. and Zweifel, P. (1996) Women's role in the provision of long-term care, financial incentives, and the future financing of long term care, in R. Eisen and F.A. Sloan (eds.): Long-term care: Economic Issues and Policy Solutions (Kluwer Academic Publishers, Boston), 79-102.

Marmot, M. (2004) The Status Syndrome. How Social Standing Affects Our Health and Longevity. Time Books, New York.

OECD (2005) Ensuring Quality Long-Term Care for Older People. Policy Brief, March 2005. 
Rainer, H. and Siedler, T. (2005) O Brother, Where Art Thou? The Effects of Having a Sibling on Geographic Mobility and Labor Market Outcomes, Discussion Paper No. 513, CRIEFF, School of Economics and Finance, University of St Andrews.

Romøren, T. I. (2003) Last Years of Long Lives. The Larvik study. London: Routledge.

Røed, K. and Strøm, S. (2002) Progressive Taxes and the Labor Market: Is the Trade-off between Equality and Efficiency Inevitable?, Journal of Economic Surveys, Vol. 16 , No $1,77-111$

Seshamani, M. and Gray, A. (2004) Time to death and health expenditure: an improved model for the impact of demographic change on health care costs. Age and Ageing, Vol. 33, 556-561.

Schultz, R., Mendelsohn, A., Haley, W. E., Mahoney, D., Allen, R. S., Zhang, S. Thomson, L. and S. H. Belle (2003) End-of-Life Care and the Effects of Bereavement on Family Caregivers of Persons with Dementia. New England Journal of Medicine 2003, No. 349, 1936-1942.

Spiess, C. K. and Schneider, A. U. (2003) Interactions between care-giving and paid work hours among European midlife women, 1994 to 1996. Ageing \& Society, Vol. 23, 41-68.

Spillman, B. C. and Lubitz, J. (2000) The effect of longevity on spending for acute and long-term care. New England Journal of Medicine, Vol. 342, 1409-1415.

Vaage, O. F. (2002) Til alle døgnets tider. Tidsbruk 1971-2000. Statistisk sentralbyrå, Oslo-Kongsvinger.

Van Houtven, C. H. and Norton, E. C. (2004) Informal care and health care use of older adults, Journal of Health Economics, Vol. 23, 1159-1180.

Wolf, D. A. and Soldo, B. J. (1994) Married Women's Allocation of Time to Employment and Care of Elderly Parents, The Journal of Human Resources, Vol. 29, No. 
4, 1259-1276.

Wolff, J. L, Dy, S. M., Frick, K. D., and Kasper, J. (2007): End-of-Life Care. Findings From a National Survey of Informal Caregivers. Archives of International Medicine, Vol. 167, No. 1, 40-6. 
Table 1

The Data

\begin{tabular}{l|c}
\hline Number of individuals born in the period 1933-1967 & 1808174 \\
$\begin{array}{l}\text { Number observed to have lost a parent in 1993-2005 and who were below 67 years } \\
\text { when the parent died }\end{array}$ & 515325 \\
$\begin{array}{l}\text { Number observed to have lost a married parent in 1993-2005 and who were below } 67 \\
\text { years when the parent died }\end{array}$ & 280897 \\
$\begin{array}{l}\text { Number observed to have lost a lone parent in 1993-2005 and who were below } 67 \\
\text { years when the parent died }\end{array}$ & 308706 \\
$\begin{array}{l}\text { Mean age at the time of loss of married parent } \\
\text { Mean age at the time of loss of lone parent }\end{array}$ & 46.6 \\
\hline
\end{tabular}

Note that this number is smaller than the sum of those who have lost a married parent and a lone parent, as some people lost both a married parent and a lone parent within the given time period. 

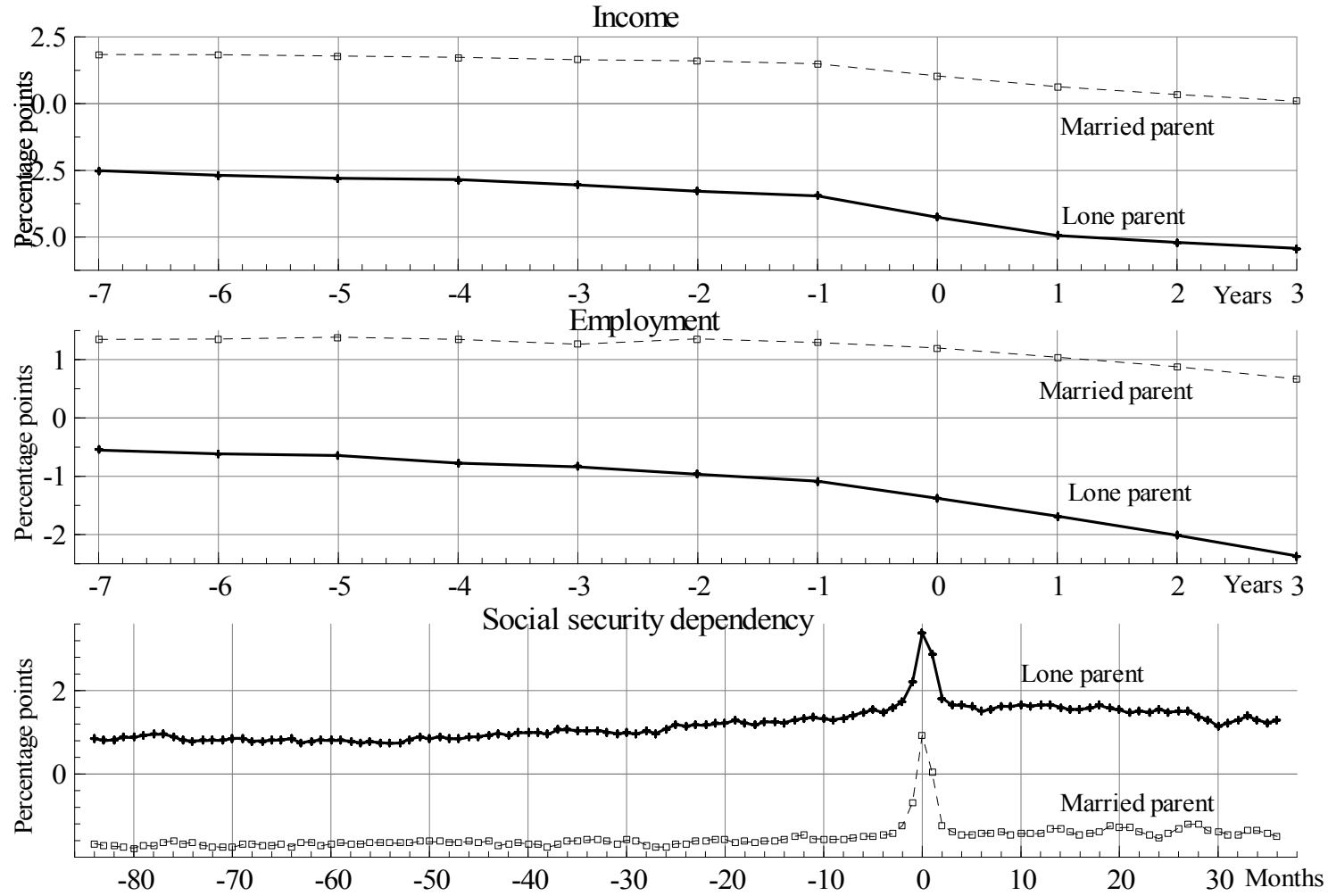

Figure 1. The percentage point difference in income, employment and social security dependency associated with the demise of a married or a lone parent.

Note: The events occur at time 0 . Income/employment is measured yearly, from 7 years before the event to three years after. Social security dependency is measured monthly from 84 months before the event to 36 months after. 

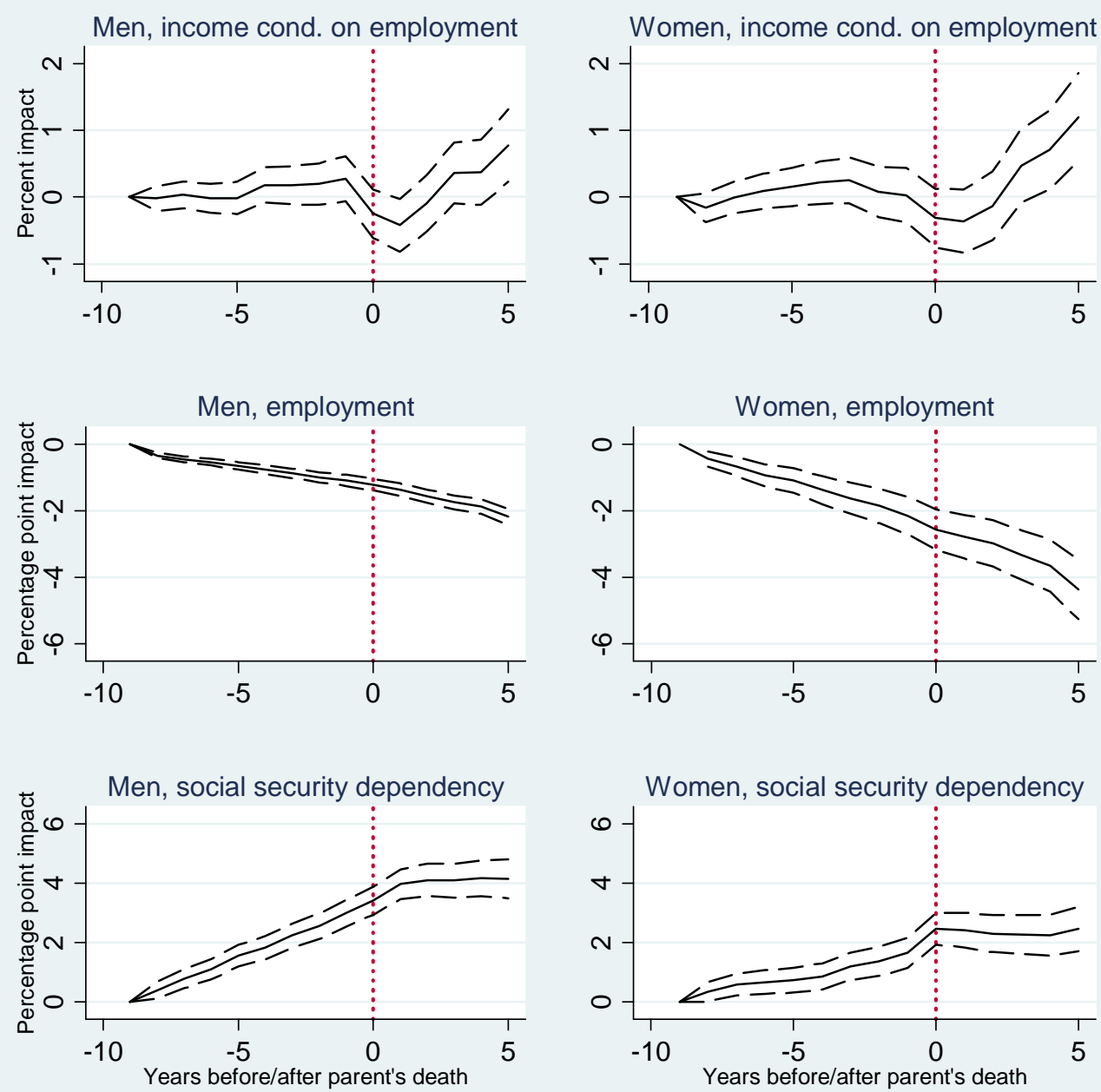

Figure 2. Estimated impacts of time (years) to loss of a lone parent (with 95 percent confidence intervals).

Note: Upper panels (earnings effects) based on fixed effects log-linear model. Middle and lower panels based on logit models (with robust standard errors). All regressions include around 700 cohort-year(age) dummy variables. 

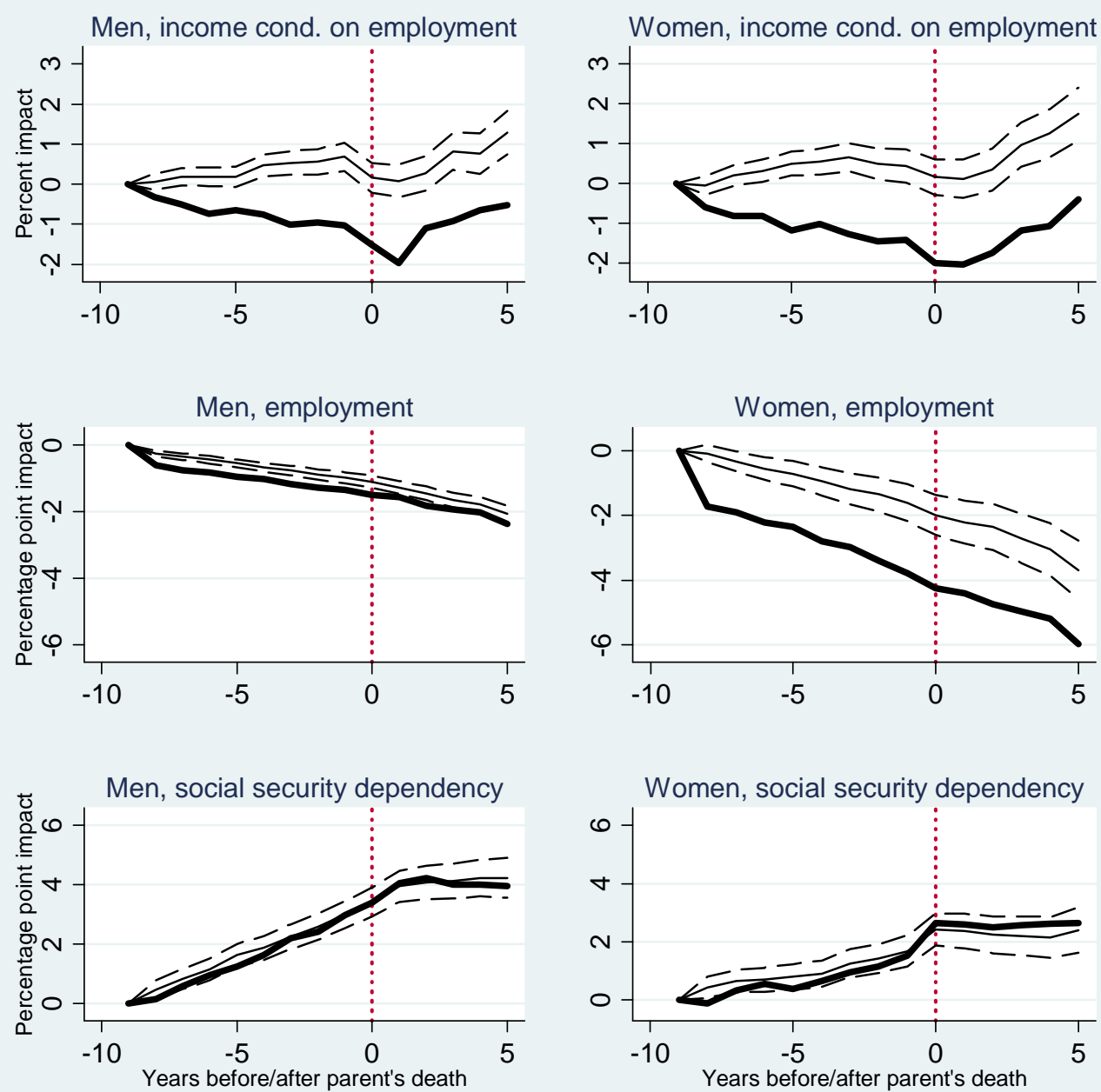

Figure 3. Estimated impacts of time to loss of a lone parent for children with siblings (thin line, with 95 percent confidence intervals) and for lone children (bold line).

Note: Upper panels (earnings effects) based on fixed effects log-linear model. Middle and lower panels based on logit models. All regressions include around 700 cohort-year(age) dummy variables, and cohort time effects are assumed to be the same for children with and without siblings. 

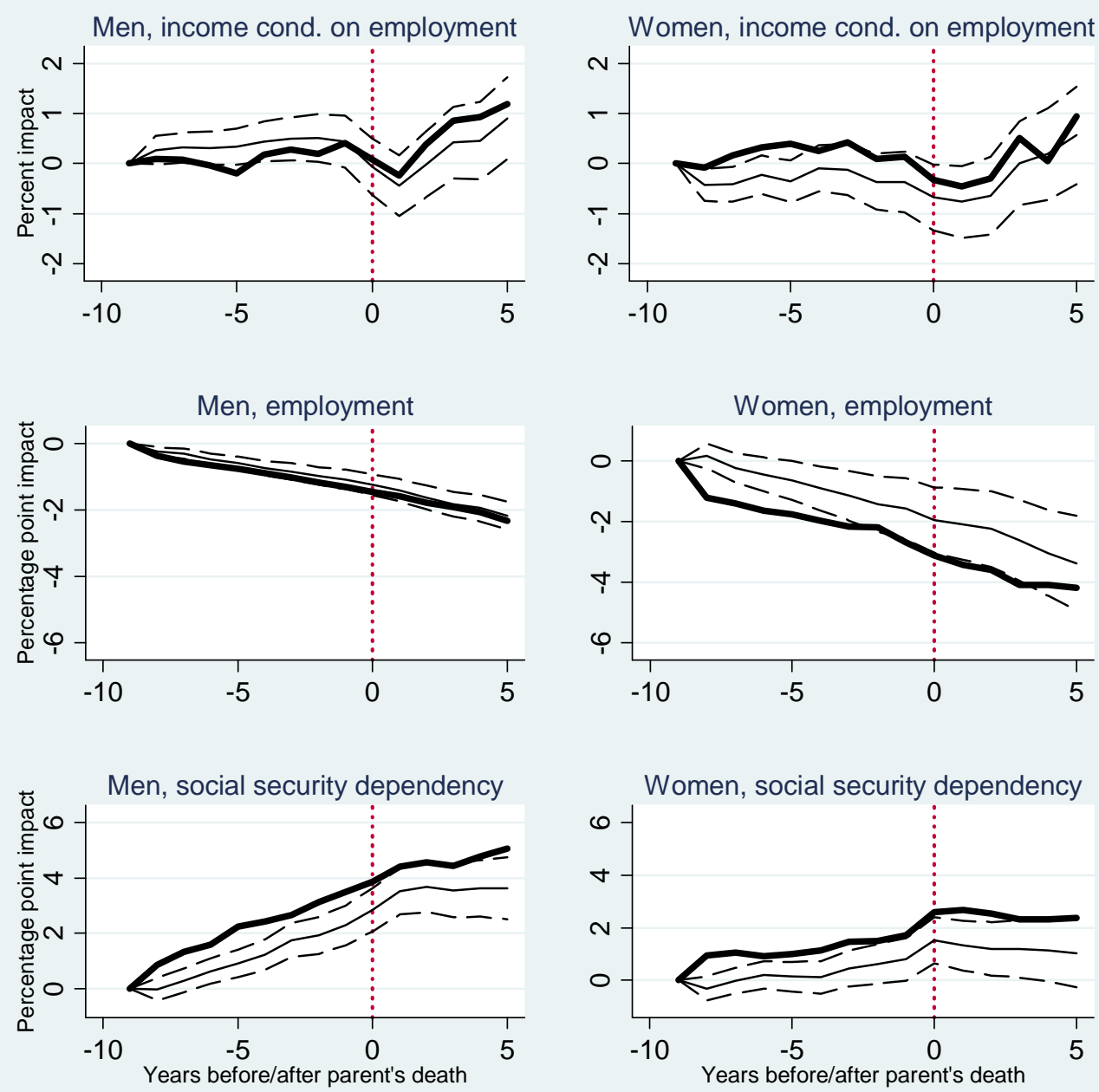

Figure 4. Estimated impacts of time to loss of a lone parent when the parent lives in an institution oriented municipality (thin line, with 95 percent confidence intervals) and when the parent lives in a home care oriented municipality (bold line).

Note: Upper panels (earnings effects) based on fixed effects log-linear model. Middle and lower panels based on logit models. All regressions include around 700 cohort-year(age) dummy variables, and cohorttime effects are assumed to be the same for both types of municipalities. 

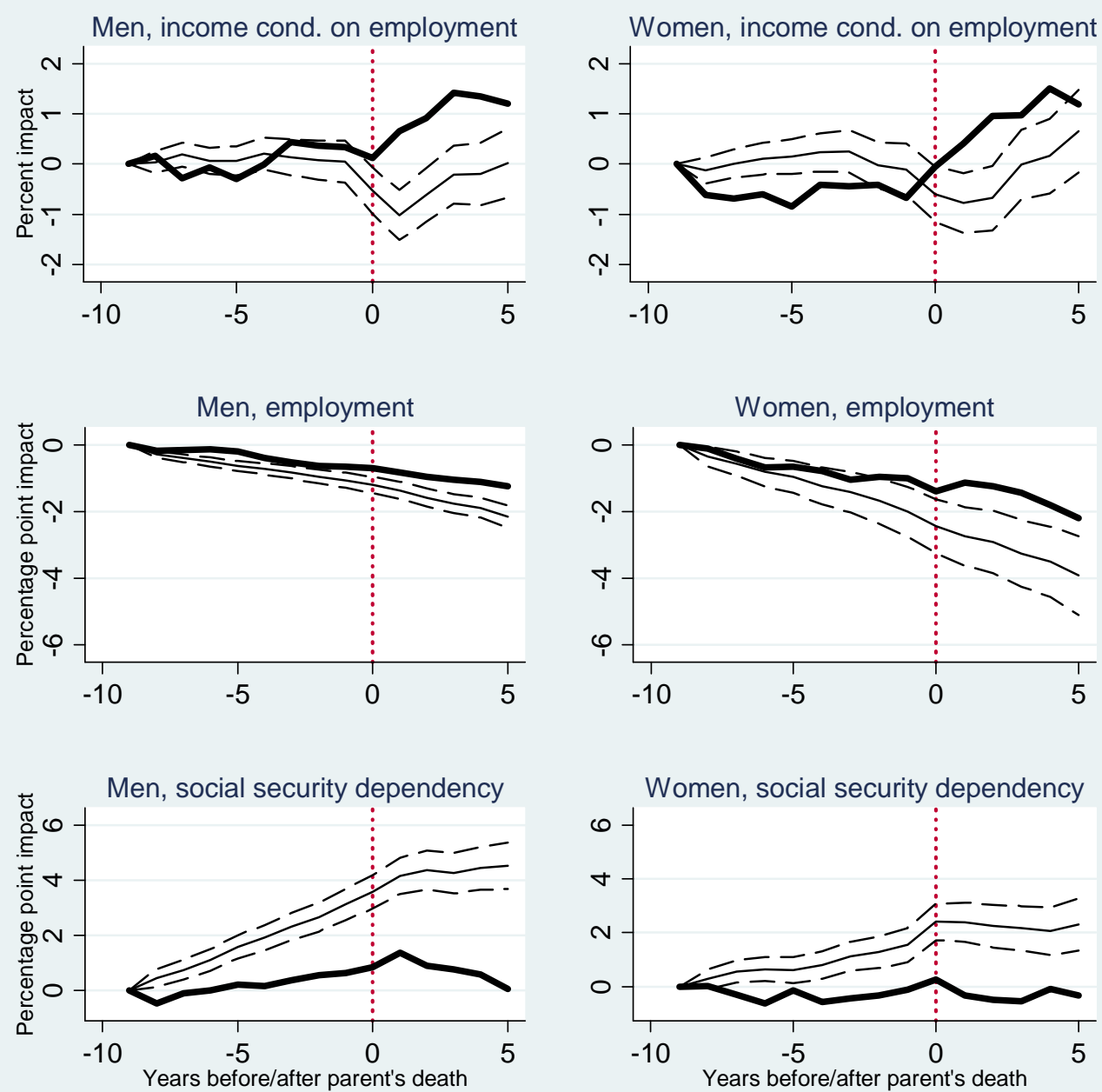

Figure 5. Estimated impacts of time to loss of a lone parent for offspring who expect a significant inheritance (thin line, with 95 percent confidence intervals) and for offspring who expect little or no inheritance (bold line).

Note: Upper panels (earnings effects) based on fixed effects log-linear model. Middle and lower panels based on logit models. All regressions include around 700 cohort-year(age) dummy variables, and cohorttime effects are estimated separately for each group. 

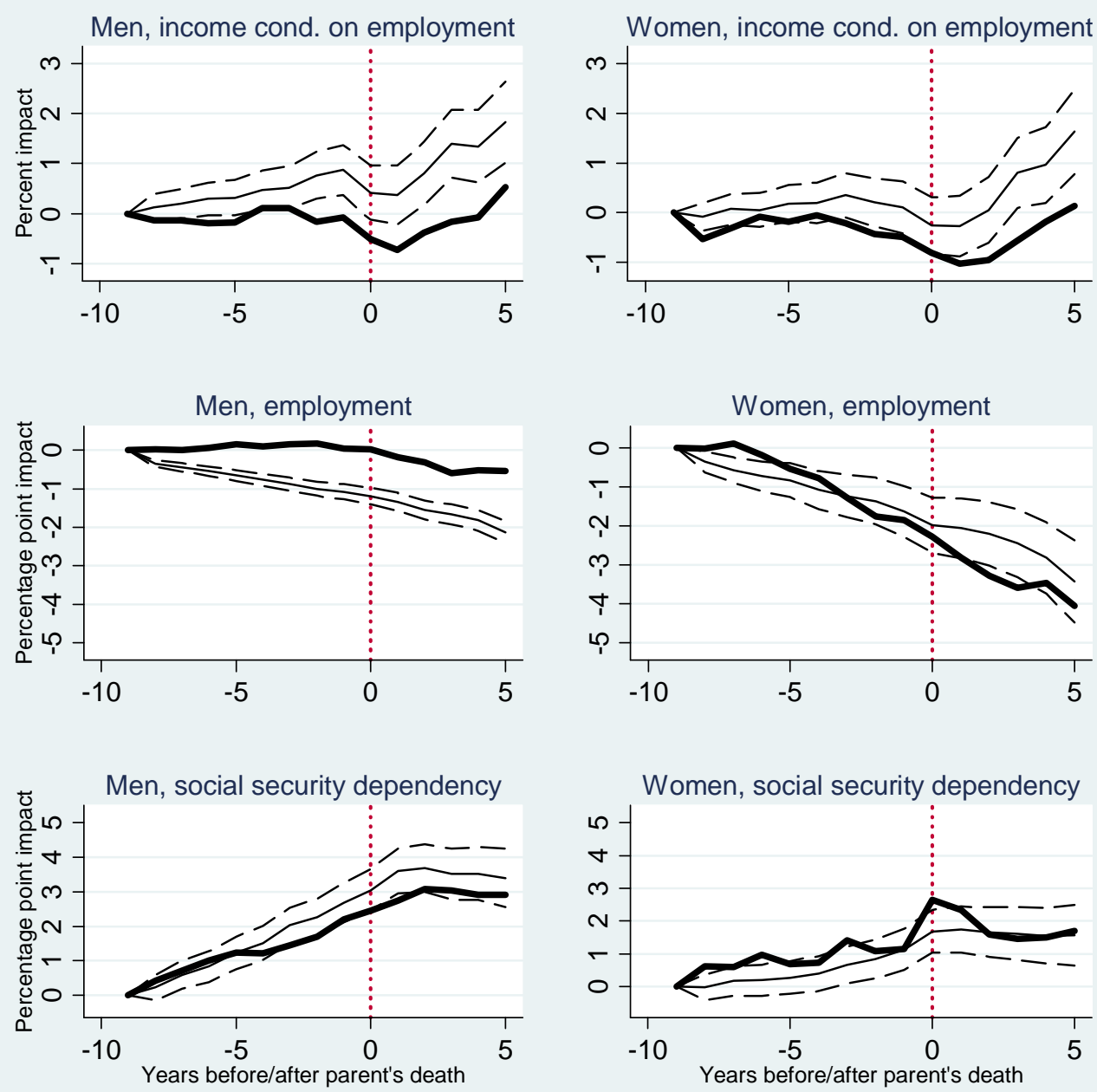

Figure 6. Estimated impacts of time to loss of a lone parent for offspring with low education (thin line, with 95 percent confidence intervals) and for offspring with high education (bold line).

Note: Upper panels (earnings effects) based on fixed effects log-linear model. Middle and lower panels based on logit models. All regressions include around 700 cohort-year(age) dummy variables, and cohorttime effects are estimated separately for each group. 

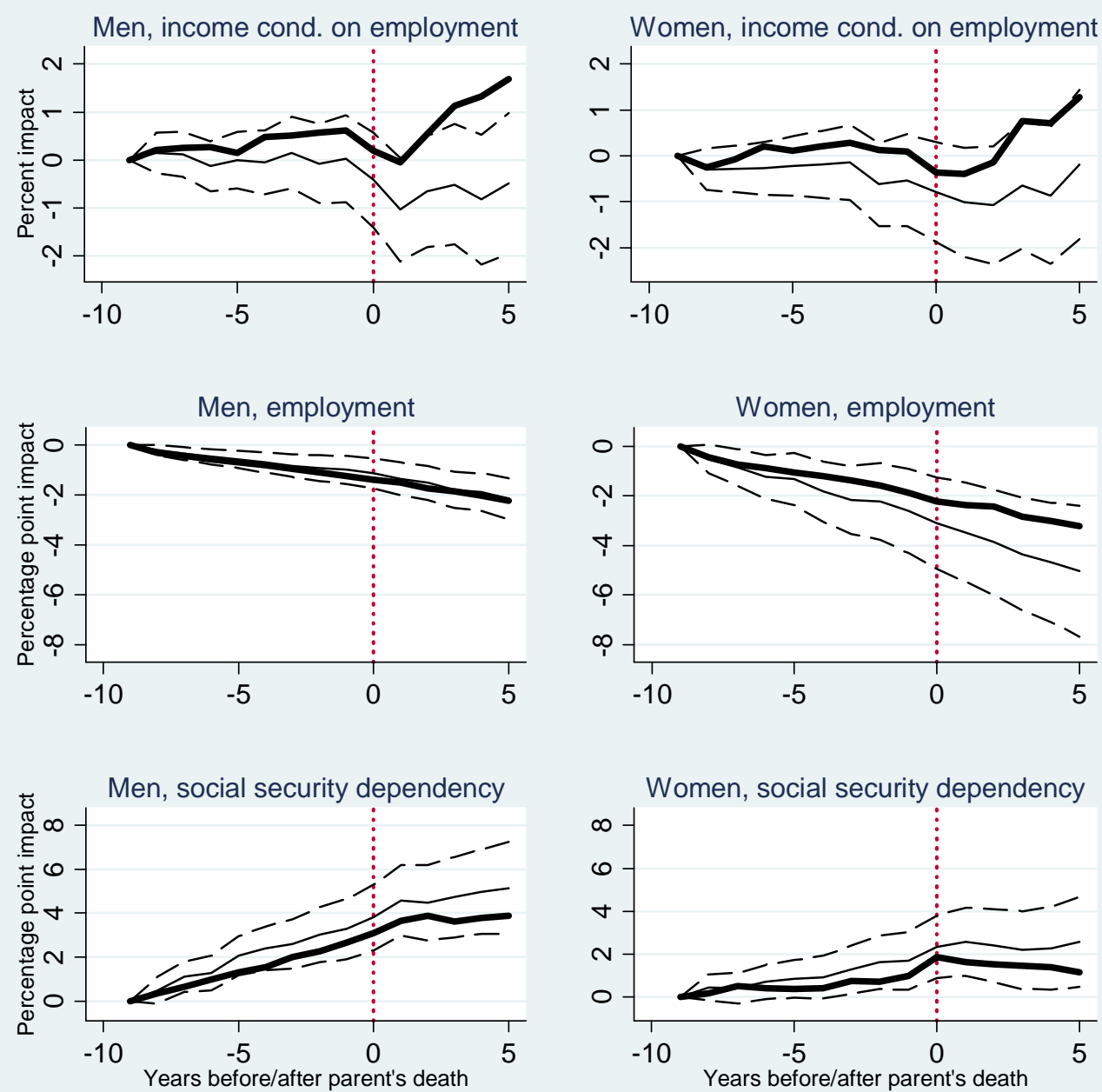

Figure 7. Estimated impacts of time to loss of a lone parent for offspring who live in another travel-to-work area than the parent (thin line, with 95 percent confidence intervals) and for offspring who live in the same travel-to-work area (bold line).

Note: Upper panels (earnings effects) based on fixed effects log-linear model. Middle and lower panels based on logit models. All regressions include around 700 cohort-year(age) dummy variables, and cohorttime effects are estimated separately for each group. 

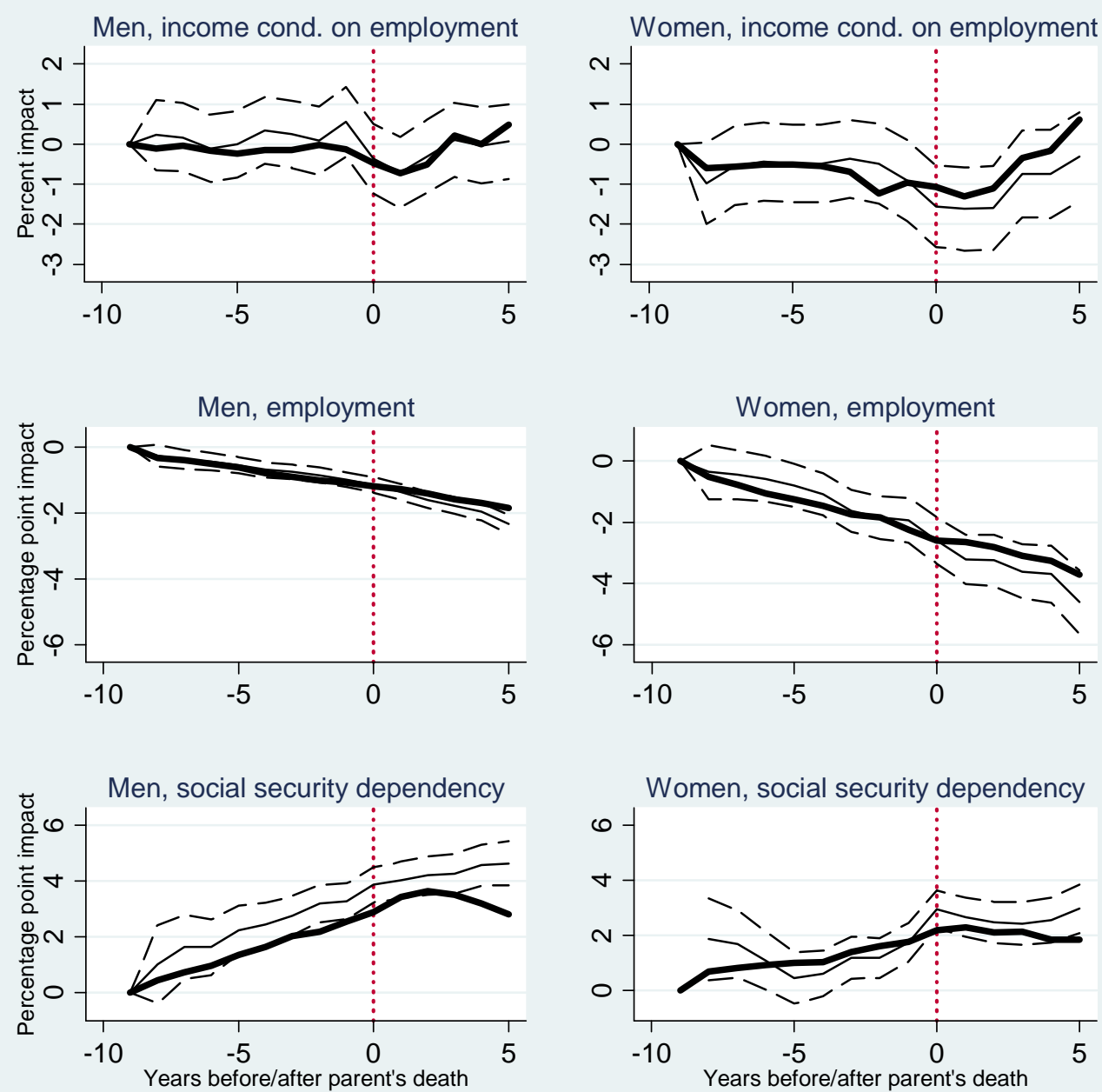

Figure 8. Estimated impacts of time to loss of a lone parent for offspring who are 38-44 years at the time of the parent's death (thin line, with 95 percent confidence intervals) and for offspring who are more than 55 years at the time of the parent's death (bold line).

Note: Upper panels (earnings effects) based on fixed effects log-linear model. Middle and lower panels based on logit models. All regressions include around 700 cohort-year(age) dummy variables. 